\title{
PERIDURAL ANAESTHESIA AND ANTI-COAGULANT THERAPY
}

\author{
George P. VArKey, M.B., F.R.C.P.(C) and G. Fred Brindle, M.D., F.R.C.P. (c) $\dagger$
}

Continuous permural anAesthesia is a useful method of providing pain relief in patients with occlusive peripheral vascular disease and consequent limb gangrene. Although it is not known if the "sympathetic block" thus achieved improves peripheral circulation, a "warm" extremity and relief of pain seem desirable goals. There are a few reports of spinal peridural haemorrhage as a complication of peridural anaesthesia in patients receiving anti-coagulant therapy. Gringrich, ${ }^{1}$ Butler, ${ }^{2}$ Helperin ${ }^{3}$ and DeAngelis ${ }^{4}$ report such complications in association with the catheter technique of continuous peridural anaesthesia, and this report further emphasizes this particular complication.

\section{Case Report}

A 70-year-old man was admitted on January 15, 1972, with a two-day complaint of progressively worsening pain and paraesthesia in the left leg. There was no history to suggest preceding illness or trauma. In particular, he denied restricted exercise tolerance, intermittent claudication or bladder or bowel dysfunction. He was not taking any medication. He had been an active farmer all his life.

The patient was febrile and somewhat confused, the pulse rate was $78 / \mathrm{min}$, and the BP $210 / 110 \mathrm{mHg}$. There were signs suggesting left ventricular enlargement and aortic sclerosis. He was in considerable pain; the left and right leg were swollen, cold and ecchymotic. The left and right posterior tibial and dorsalis pedis pulses were not palpable. A clinical diagnosis of atherosclerotic cardiovascular disease and aneurysm of left popliteal artery with embolization distal to it, was made.

We were requested to provide peridural anaesthesia principally for relief of pain and accordingly a 16-gauge Tuohy needle was introduced through the L3L4 interspace, through which a \#18 teflon peridural catheter (Deseret) was introduced and directed $4 \mathrm{~cm}$ cephalad. The entire procedure was considered technically satisfactory; in particular, there was no evidence to suggest inadvertent trauma to a peridural blood vessel. The first injection of $5 \mathrm{ml}$ of 1 per cent mepivacaine (Carbocaine ${ }^{\circledR}$ ) completely relieved the patient's pain; subsequently the same dose of mepivacaine was administered every three hours after a test of aspiration through the peridural catheter.

The patient was started on anti-coagulant therapy (intravenous heparin) within 20 minutes after the first peridural injection. Twenty-four hours later he com-

- Present address: Dept. of Anaesthesia, University Hospital, London, Ontario.

tDepartment of Anaesthesia, Centre Hospitalier Universitaire, Sherbrooke. 
plained of urinary incontinence. The following day ( 17 January) he complained of severe low back pain on injection of the anaesthetic agent, which seemed to remit after the catheter was withdrawn about $1 \mathrm{~cm}$. An aortogram showed moderate stenosis of the left renal artery close to its origin, severe degenerative and calcific changes in both femoral arteries, aneurysmal dilatation of left popliteal artery and non-opacification of the vessels distal to the aneurysm; vascular surgery on the right leg was considered but ultimately rejected.

An above-knee amputation of the left leg was performed on January 18, with continuation of the same peridural anaesthesia for the operation. Heparin therapy was discontinued. The patient remained pain-free post-operatively with injection of $5 \mathrm{ml}$ of 1 per cent mepivacaine through the peridural catheter every three hours. On January 20 , the peridural catheter was removed.

Urinary incontinence occurred after withdrawal of peridural anaesthesia and there was faecal incontinence on January 28. Subsequent clinical evaluation suggested a cauda equina lesion with sensory, motor and reflex abnormality in the distribution of $\mathrm{L5}$ and the sacral nerve roots. A myelogram showed a peridural compressive lesion at L3-L4 level and at operation a well-defined spinal peridural haematoma was encountered at that level and evacuated. There has been little change in the clinical findings post-operatively.

\section{Discussion}

Anticoagulant therapy is conventional in the management of occlusive peripheral vascular disease. While these agents reduce the thromo-embolic complications, they add the hazard of bleeding. Allen ${ }^{5}$ wrote on the complications of anti-coagulant therapy in 1949 and Alexander ${ }^{6}$ dealt with the problem more specifically in 1955, reporting several cases of spontaneous spinal epidural haematomata in patients receiving anti-coagulant therapy.

The posterior vertebral and peridural veins are of the embryonic type without valves and the pressure in these vessels is very much lower than that in the general venous system. Spontaneous rupture of the peridural veins with bleeding into the surrounding areolar tissue has been reported by Lougheed, ${ }^{7}$ Winer, ${ }^{8}$ Spurny, ${ }^{9}$ Jacobson, ${ }^{10}$ and Markham. ${ }^{11}$ The catheter may damage a blood vessel during insertion or due to sliding movements in the peridural space produced by flexion or extension of the patient's spine. In our patient these delicate vessels could have been injured by the peridural catheter with subsequent development of a peridural haematoma because of the prolonged clotting time consequent on anti-coagulant therapy. The haematoma acted as an intraspinal space-occupying lesion compressing the nerve roots of the cauda equina. Sreerama et al..$^{12}$ recently reported ten intracranial and one epidural haematomata and questioned the long-term value of anti-coagulant treatment. They emphasized the possibility of spontaneous haematoma formation in patients on anti-coagulant therapy and also its possibility after insignificant trauma. DeAngelis reports a patient on anticoagulant therapy who developed a lumbar subarachnoid haematoma after a diagnostic lumbar subarachnoid puncture. The same reporter cites five cases in which patients were given heparin after an epidural catheter had been inserted. 
In one patient the infusion of heparin was begun 16 hours after the epidural catheter was in place and during the next 6 hours paralysis of the lower extremities developed with a sensory deficit to the level of the tenth thoracic segment.

Standard textbooks generally advise that peridural anaesthesia, especially the continuous technique, should be avoided in patients with spontaneous or iatrogenic coagulation defects. The issue is less clear in those situations where continuous peridural anaesthesia is used and in which anti-coagulation may subsequently be started. It is difficult to appreciate the real incidence of epidural haematomata since relatively few cases have been reported. One wonders how many cases go unreported because of fear of possible legal action.

We know that many cases have been reported in patients on anti-coagulant therapy who have not been traumatized either by accident or by an anaesthetist introducing a large-bore peridural needle.

Our experience has cautioned us against the use of peridural anaesthesia in patients receiving anti-coagulant therapy. However, if this method of anaesthesia is imperative in such a patient, then great care must be exercised to detect early manifestations of spinal cord or cauda equina compression. The evaluation of sensory and motor symptoms may be difficult in a patient receiving peridural anaesthesia, and an elderly patient may not mention symptoms suggesting nerve root compression. These are additional factors warranting repeated careful neurological evaluation. An early symptom of peridural haematoma is severe back pain. ${ }^{3,4}$ If this is noted, urgent neurological assessment is required with subsequent myelography and surgical exploration as indicated. A detailed neurological examination should be carried out to ascertain the integrity of the spinal cord and roots prior to injecting subsequent doses of the local anaesthetic agent. At the first sign of weakness, numbness, paraesthesiae or lower extremity pain, the presence of a haematoma should be suspected.

\section{SUMMARY}

A 70-year-old man with occlusion of the popliteal artery and progressive gangrene of the leg received peridural analgesia with an indwelling catheter. There was gratifying relief of pain. He was then started on anti-coagulant therapy. Symptoms of urinary incontinence, severe low back pain and faecal incontinence developed and persisted after withdrawal of the peridural catheter. The clinical impression of a cauda equina lesion causing this deficit was confirmed by myelography when an extradural compressive lesion was demonstrated at L4 level. At operation a peridural haematoma was evacuated from this site.

Our experience with this complication of peridural anaesthesia is documented to caution against the use of this technique in patients who are receiving or who might subsequently receive anti-coagulant therapy.

\section{RÉSUMÉ}

Nous avons fait une analgésie péridurale avec un catheter à un homme de 70 ans qui souffrait d'une occlusion de l'artère poplitée et d'une gangrène progressive 
de la jambe. Il s'en suivit un soulagement bienfaisant. On commença alors une thérapie aux anticoagulants. Sont apparues et ont continué d'exister après avoir enlevé le catheter: une incontinence urinaire, de pénibles douleurs au bas du dos et de l'incontinence des selles. Nous avions l'impression clinique que ce syndrome était dû à une lésion de la queue de cheval, ce que confirma une myélographie qui mit en évidence, en $\mathrm{L} 4$, un lésion compressive extradurale. A l'opération, de cet endroit, on a évacué un hématome péridural.

Devant cette complication vécue avec l'anesthésie péridurale, nous conseillons la prudence dans l'usage de cette technique chez les malades recevant ou susceptibles de recevoir ultérieurement une thérapie aux anti-coagulants.

\section{REFERENCES}

1. Gincrich, T.F. Spinal epidural hematoma following epidural anesthesia. Anesthesiology 29: 162 (1968).

2. Butler, A.B. \& Green, C.D. Haematoma following epidural anaesthesia. Canad. Anaesth. Soc. J. 17: 635 (1971).

3. Helperin, S.W. \& CohEn, D.D. Hematoma following epidural anesthesia: report of a case. Anesthesiology 35: 641 (1971).

4. DeAngelis, J. Hazards of subdural and epidural anaesthesia during anticoagulant therapy: case reports and review. Anaesthesia and Analgesia 51:676 (1972).

5. Allen, A.W. Complications of anticoagulant therapy. Surgery 26: 957 (1949).

6. Alexander, B. Coagulation-hemorrhage and thrombosis. New England Journal of Medicine 252: 432 (1955).

7. LougheEd, W.M. \& Hoffman, H.J. Spontaneous extradural hematoma. Neurology 10: $1059(1960)$.

8. Winer, B.M., Honenstein, S., Stanr, A.N. Spinal epidural haematoma during anticoagulation therapy. Circulation 19: 735 (1959).

9. Spurny, O.M., Rubin, S., Wolf, J.W., \& Wu, W.Q. Spinal epidural hematoma: two cases. Arch. Int. Med. 114: 103 (1964).

10. Jacobson, J., Maccabe, J.J., \& Harris, P. Spontaneous spinal epidural hemorrhage during anticoagulation therapy. British Medical Journal 1: 522 (1966).

11. Markham, J.W., Lynge, H.N., \& Stahlman, G.E. The syndrome of spontaneous spinal spidural hematoma: report of three cases. J. Neurosurgery 26: 334 (1967).

12. Sreerama, V., Ivan, L.P., Dennery, J.M., \& Richard, M.T. Neurosurgical complications of anticoagulant therapy. Canadian Medical Association Journal 108: 305 (1973). 